\title{
A Cross-Departmental Approach to Supporting Students with a Disability Affecting Foreign Language Acquisition
}

\author{
Franziska Lys, Alison May, Jeanne Ravid
}

In order to enhance mobility, competitiveness, and opportunities for work, the European Union lists the ability to communicate in a foreign language and to understand another culture as an important objective in their language education policy. Knowledge of a foreign language is also an important objective for many American universities, which require students to study a foreign language as a prerequisite to graduate. Students with documented disabilities affecting the learning of a foreign language or students with poor foreign language learning skills, therefore, pose a significant challenge, since a foreign language requirement may prevent such students from graduating unless universities are willing to make special arrangements such as having students graduate without fulfilling the requirement or letting them take substitution classes. The question of what to do with such students is at the heart of this article. It describes how one mid-sized private university with a two-year language proficiency requirement has approached the problem to ensure that policies are implemented fairly. Rather than pulling students out of the foreign language classroom, the university succeeded in keeping students engaged with foreign language study through advising and mentoring across departments.

Keywords

Foreign language proficiency; foreign language learning disability; disability; foreign language waiver; foreign language acquisition; academic advising

\section{The Study of Foreign Languages as Part of a Global Education}

With globalization as a driving force, foreign language study has become an increasingly essential component of education. Multilingual and intercultural skills and the appreciation of different cultures are important to enhance global understanding. Knowledge of a foreign language has long been 
a fundamental principle of the European Union's language and language education policy. The European Commission's White Paper on Education and Training published in 1995 lists proficiency in three community languages as one of its general objectives: “... it is becoming necessary for everyone, irrespective of training and education routes chosen, to be able to acquire and keep up their ability to communicate in at least two Community languages in addition to their mother tongue" ("White Paper on Education and Training" 47). More recently, the European Parliament and the Council have listed knowledge of foreign languages as one of eight key competences for lifelong learning, recognizing that mobility and job possibilities are intrinsically linked to multilingual and intercultural skills. They define knowledge of a foreign language broadly, as "...the ability to understand, express and interpret concepts, thoughts, feelings, facts and opinions in both oral and written form (listening, speaking, reading and writing) in an appropriate range of societal and cultural contexts (in education and training, work, home and leisure) according to one's wants or needs ("Recommendation of the European Parliament and of the Council")". Because European countries are diverse with respect to their language situation, the recommendation makes no specific proposal with regard to the level of proficiency desired but leaves it up to each country to implement and follow the recommendation. ${ }^{1}$

In the United States, many universities also recognize language learning as an essential component of education, and they require foreign language study either on the home campus or as part of a study abroad program as a prerequisite to graduate. Consistent with European countries, the amount of foreign language study that universities with a language requirement specify varies considerably across schools and universities. The Weinberg College of Arts and Sciences at Northwestern University, for example, has a two-year foreign language requirement, which means that a student will have to study two years of one language (or the equivalent) at the college level in order to graduate. In contrast to language learning policies in Europe, which recommend foreign language education within the first few years of schooling, most students entering Northwestern University as freshmen will have begun their formal foreign language instruction as late as age 12 or 13. The majority of these students, therefore, will not have achieved a high enough level to pass the foreign language requirement by the time they enter college. ${ }^{2}$ In order to fulfill the foreign language requirement, students will continue with the language they started in junior high and/or high school, or they will begin a new language. Students who plan to continue with the language they already 
started will take a placement exam to determine which language class would be the most appropriate to build on their existing language skills.

\subsection{Students with Difficulties Learning a Foreign Language}

For universities that have a foreign language requirement, students who exhibit poor foreign language learning skills and students with documented disabilities affecting second language acquisition therefore pose a significant challenge. Simply put, if they cannot pass the foreign language requirement, they cannot graduate. While colleges and universities are not obligated to waive foreign language requirements (see Section 3.2 below), many do provide course substitutions to students with documented disabilities if they are otherwise qualified to ensure that these students can graduate. The decision to limit foreign language support to students with documented disabilities at most institutions, including Northwestern University, is that a student being evaluated for and diagnosed with a disability (other than a disability adversely impacting intelligence quotient, IQ, which Northwestern University's rigorous admission criteria screen out) objectively rules out low intelligence and poor motivation or laziness as the primary cause for a student's difficulty with foreign language. The diagnosis of a disability therefore legitimizes the need for additional support.

The established policies on what constitutes a "foreign language disability" and what accommodations a school is willing to provide (Mangrum and Strichart), however, differ a great deal. Universities and schools set their own testing and procedural requirements: some will accept full documentation of a previously diagnosed disability; others require additional testing on, for example, the Modern Language Aptitude Test (MLAT) (Carroll and Sapon) or evidence of having previously attempted a foreign language course and failed. Accommodations can range from a complete waiver of the foreign language requirement to course substitutions such as foreign culture courses or literature courses taught in English translation. Many universities grant waivers or course substitutions to students based on their test scores alone without ever having been enrolled in a foreign language course (e.g., Sparks, Philips, and Javorsky, "Students classified as LD who received course substitutions" 487 and "Students classified as LD who petitioned for or fulfilled the foreign language requirement" 355).

Given the fact that the term "foreign language learning disability" is contested (see Sparks, "Evidence-based accommodation decision making" 544) and that many experts in the field argue that students have responsibility 
for legitimate efforts before substitution is considered (e.g., Jarrow and Fink), the Weinberg College of Arts and Sciences at Northwestern University set up procedural steps under the supervision of the Language Proficiency Committee for establishing a course substitution process. The main goal of the substitution process is for students to first engage in language classes while being closely monitored to offer timely interventions and accommodations, and only allow for substitution classes when progress cannot be guaranteed. These procedural steps were established because this University believes that every student will benefit from exposure to a foreign language and culture, regardless of proficiency level achieved or classes taken. It is noteworthy that a number of other schools at Northwestern University are following suit, implementing or increasing their own already-existing foreign language requirements.

\section{Individual Variations in Foreign Language Learning}

\subsection{Comparing the Acquisition of L1 and L2}

Virtually everybody learns and masters his or her first language (L1) with relative ease. Learning a second language $\left(\mathrm{L}_{2}\right)$, however, is significantly harder: individuals vary considerably in the rate at which they learn a second language and in the proficiency level they ultimately achieve. There are many factors that are associated with success or failure in language learning, from age at which the second language is learned to the specific learning environment, to varying language learning aptitude, personality characteristics (e.g., being willing to take risks, having high self-esteem, having a positive attitude, and being inquisitive), motivation, and anxiety. Briefly reviewing some of the major differences in how $\mathrm{L}_{1}$ and $\mathrm{L}_{2}$ are acquired may help explain why individuals' second language learning is so inconsistent. ${ }^{3}$

Learning a first language is an essential part of growing up and mirrors a child's social and cognitive development. In contrast to Europe, however, most second languages in the United States are learned later in life when social and cognitive factors such as anxiety, motivation, attitude, cognitive styles, personality, learning styles and learning strategies may affect the language learning process in a unique way. For example, recent research has confirmed that among different affective variables, language anxiety can affect students' achievement or performance. Learners who exhibited a high foreign language anxiety were less likely to succeed, even across different target languages (Horwitz; Liu and Huang; Olivares-Cuhat). 
The way children learn their first language is unique: they learn it naturally through interactions with adults and children and they learn it in a more or less uniform learning environment with language input that is plentiful and tailored to the emotional and cognitive level of the child. 4

In the United States, most second languages are learned in formal classrooms through instruction of one kind or another. This process often requires conscious learning of vocabulary and grammar rules and is quite distinct from the more natural way a child acquires language as expressed in Krashen's well-known distinction between learning and acquisition ("Second language acquisition and second language learning"). Exposure to the target language is also crucial for L2 learning (Krashen, "The Input Hypothesis: Issues and Implications"), as the amount and quality of comprehensible input a learner receives determines the rate of learning. Unfortunately, formal classroom instruction often does not provide sufficient target language input. Research furthermore has shown that conversational adjustments such as for example confirmation checks, comprehension checks, clarification requests, reformulations, or topic-focused questions successfully modify the input and influence subsequent task performance (e.g., Ellis; Gass; Gass and Selinker; Gass and Varonis; Larsen-Freeman and Long; Mackey and Philp; Pica). However, L2 learners are often not exposed to extended discourse because classroom practices limit the discussion to a question and answer format (Donato and Brooks; Mantero). Furthermore, when learning their first language, children are exposed to one phonological system, one set of grammar rules, one system of syntactic rules, and one lexicon. L2 learners need to make sense of a second language system that might be quite different from their first. Ziegler and Goswami, for example, point out that languages vary in the consistency with which phonology is represented in orthography and that the development of reading in L2 may depend on the mastery of the lexical organization and phonological representation of the target language. Marinis draws attention to the fact that $\mathrm{L}_{2}$ learners do not only have to acquire the target language grammar, but they also have to discover the processing strategies that belong to the target language to be successful.

Variation in language proficiency is quite evident when comparing placement test scores taken by our entering freshmen. Test scores from students with similar language learning experiences (e.g., four years of language learning on the high school level) indicated, that some may best be served by starting in an introductory language class, while others place out or nearly place out of the two-year foreign language requirement. Such discrepancies are not only 
due to variation in cognitive abilities, learning styles and learning strategies, but to a host of other reasons, e.g., quality of classroom instruction and time on task. While most freshmen adapt fairly quickly to the way languages are taught on the college level, we see a lot of variation among our learners despite excellent classroom instruction. Some learn quickly, contribute to class discussion with ease, and manage daily homework without additional help or undue pressure. Others learn slowly, seem apprehensive, do not like to speak in front of their peers in the target language, cannot remember or understand foreign words, and feel they can never be successful already at relatively early stages of acquisition.

\subsection{Variation in Learning or a Disability?}

Northwestern University is a very selective, highly research-based (known as "R1") American university, admitting only $12.9 \%$ of its applicants for the 2014-2015 academic year (Pager). Given its strong academic reputation and wide range of competitive athletic programs, it attracts students from all 50 U.S. states and, for the incoming freshman class, almost 100 countries. Most students entering Northwestern University will have graduated from their secondary schools with a grade-point average (GPA) among the top $10 \%$ in their class. Like most universities in the U.S., the admission criteria are the same for students with and without disabilities, meaning that students with disabilities are equally intelligent and capable.

Yet, every year, we see students struggle significantly to learn a foreign language. Even those who excel in other academic areas sometimes complain that no matter how much they study, they still earn low grades in their language classes. Others may experience significant nervousness and are anxious about going to class and having to speak, which prevents them from absorbing the material. The following self-reflective comments, first published by Horwitz, Horwitz, and Cope in 1986 in their volume on language learning and anxiety (125), could have been voiced by many of our students:

- "I just know I have some kind of disability: I can't learn a foreign language, no matter how hard I try."

- "When I'm in my Spanish class I just freeze! I can't think of a thing when my teacher calls on me. My mind goes blank."

What is it that prevents students from being successful language learners? Is it a learning disability (LD)? Are students' expectations too high since variations in language learning are to be expected and not everybody can be an "A" 
student? Or is it a ploy to avoid studying a subject they do not like or feel is not valued? We have seen students withdraw from foreign language classes for a variety of reasons that have nothing to do with the impossibility of learning a language, such as maintaining a higher GPA or focusing on course work that easily translates into job opportunities. Trying to figure out why a student is not succeeding in a foreign language class and how to help such a student so that she/he can graduate can be a difficult task. At Northwestern University, it is the task of the Language Proficiency Committee to find good solutions to ensure that students' best interests are put forward without abandoning the University's foreign language requirement. The development and description of this process is the focus of the remainder of this paper.

\section{Foreign Language (Learning) Disability}

\subsection{The Controversy}

In America, there has long been controversy over whether or not a discrete disability for learning a foreign language exists. For instance, one could reasonably attribute the challenges that many American students experience learning a second language to the methodology for teaching foreign language in American schools, especially the late point at which foreign languages are typically formally introduced (and therefore misaligned with critical periods for language acquisition; Otto 77). In contrast, Gajar (330) as well as $\mathrm{Hu}$ (430) argued that there was sufficient evidence in the research literature to support the existence of a foreign language learning disability (FLLD). However, the very researchers (such as Sparks, Ganschow, and many others) who are credited with introducing the concept and coining the term FLLD have since acknowledged, "Our use of the term was premature and, in retrospect, incorrect" (Sparks "Is there a disability for learning a foreign language" 544). In their research (Sparks, Philips, Ganschow, and Javorsky; Sparks, "Is there a disability for learning a foreign language" and "Evidence-based accommodation decision making"), they have found that many students who struggled with foreign language learning "were not and could not be classified as LD" (Sparks, "Evidence-based accommodation decision making" 180) and that many students with diagnosed LD successfully completed their foreign language requirements (Sparks, Philips, Ganschow, and Javorsky). Forsbach-Rothman, Padro, and Rice-Mason wrote, "Students with learning disabilities may not have any more problems learning a foreign language than 
do students with no documented disabilities" (Sparks as cited in ForsbachRothman, Padro, and Rice-Mason 23). The current position of Sparks's group is that students with significantly weaker native language skills, especially as related to phonological processing problems, tend to do more poorly in foreign language regardless of whether they are or can be accurately classified as having LD (Sparks, "Evidence-based accommodation decision" 181).

A second issue that arises with the notion of an FLLD is that evaluators are limited by the types of tests available that reliably predict the aspects of foreign language study that will be the most difficult for such students. Notably absent is the existence of a single comprehensive test or set of tests that can function in this capacity. For instance, the once commonly-administered MLAT (Carroll and Sapon) and other similar tests may demonstrate a misunderstanding of the foreign language aptitude concept, which implies foreign language aptitude is a static trait. In contrast, Sparks ("Is there a disability for learning a foreign language" 551) cites evidence from multiple studies finding significant improvements in students' MLAT scores over time as they receive foreign language instruction.

The third problem about positing an FLLD is a function of disagreements (between states, school districts, private evaluators, etc.) over how to operationalize the definition of $\mathrm{LD}$, as put forth in law. As a result of these disagreements, the breadth of tests administered and the quality of learning (and other) disability evaluations submitted can vary from student to student and provide differing levels of information to determine language and foreign language acquisition skills. Indeed, Sparks ("Is there a disability for learning a foreign language") writes, "I contend that the concept of an FLLD will naturally demonstrate the same problems that are inherent in the LD concept: the lack of a logically consistent, easily operationalized, and empirically valid definition and diagnostic criteria that are related to the definition" (546, emphasis in original). In spite of these frequently cited shortcomings of measures assessing learning disabilities and differing criteria for diagnosing a disability, Northwestern University's Office of Services for Students with Disabilities (SSD; the office that determines and assists in the provision of reasonable accommodations for qualifying students) requires that high-quality comprehensive testing demonstrating a disability according to widely agreedupon criteria be provided as evidence before a student is deemed eligible for any foreign language accommodations.

A review of the websites of schools comparable to Northwestern University (primarily Ivy League and Big 10 institutions) provides a reflection of the 
uncertainty in the disability field as to whether a foreign language disability or FLLD per se exists. The University of Wisconsin at Madison and the University of Michigan at Ann Arbor, for instance, seem to emphasize that a learning disability is the primary type of disability that interferes with foreign language acquisition ("Foreign language substitution package"; "Language Substitution"). However, schools such as Penn State, the University of Pennsylvania, and Dartmouth College are more similar to Northwestern University in their positions that various types of disabilities could prevent foreign language acquisition, and they are therefore rejecting the notion of a specific type of foreign language disability ("Course substitutions"; "Language requirement substitution"; Trustees of Dartmouth College).

Understandably, postsecondary schools' differing views regarding the existence of disabilities that significantly interfere with foreign language acquisition would be expected to influence their policy decisions regarding the institution of foreign language requirements as well as the possibility of providing waivers or course substitutions (see below, "Procedures Followed at Other Schools"). However, as multicultural competence becomes an increasingly important priority of education, the importance of foreign language requirements are also being more ardently defended (Calvin and Rider). Given the increasing desire to graduate global citizens, colleges and universities who may not previously have had a foreign language requirement may begin to adopt one, and those colleges and universities who have one may refuse to waive such requirements or to grant substitutions (e.g., Harvard and Princeton Universities; Russell; Fowler, et al., respectively), feeling as if they would be doing their students, disabled or not, a disservice.

\subsection{Legal Requirements}

As with most American laws, those pertaining to disability and education are vague and therefore open to interpretation. What can be especially confusing in terms of disability law for students entering postsecondary education is that the laws that govern students with disabilities during primary and secondary education are different from those governing postsecondary education. Specifically, the primary disability-related law governing earlier education mandates a free and appropriate public education for all students, including those with disabilities, for primary through secondary school. To ensure that students with disabilities can benefit from their education, it provides for individualized special education services, which may mean specially taught foreign language classes, tutoring in foreign language and in some cases 
foreign language waivers, all at no cost to the student or her/his family.

At the postsecondary level, American laws mandate only "reasonable accommodation" of disability intended to allow professors to teach their classes the way they normally would with the addition of minor academic adjustments or auxiliary aids and services for qualifying students. Reasonable accommodation is determined through a review of disability documentation and may include services such as proctoring students' accommodated exams, paying for note-takers, arranging for sign-language interpreters, and so on. However, postsecondary disability laws do not mandate changes to the curriculum, to the way in which it is taught or to the essential elements of a course. Consistent with these laws, SSD notes on its website:

A reasonable accommodation is a modification or adjustment to a course, program, service, or activity that enables a qualified student with a disability to obtain equal access. Equal access means an opportunity to attain the same level of performance or to enjoy equal benefits and privileges as are available to a similarly situated student without a disability. ("Reasonable accommodations and services")

Postsecondary programs can therefore designate what they deem to be essential elements of their curricula, which may include a foreign language requirement, and even if these essential elements pose an extreme difficulty or prove impossible for students with certain disabilities, these essential elements do not need to be modified and certainly not waived.

\subsection{Procedures Followed at Comparable Schools}

Colleges and universities range from having no foreign language requirement (e.g., Brown University, "Advisee handbook: A student guide to the Brown first-year advising process") or making the provision for a foreign language waiver (e.g., Dartmouth College and in some instances Yale College, see "Skills requirement") to explicitly stating that no foreign language waiver or substitution courses will be made (e.g., Harvard and Princeton Universities; Russell; Fowler, et al.). Jarrow and Fink discourage foreign language waivers and instead propose modifying courses and allowing occasional substitutions, and this middle-ground approach appears to be the most common among American universities. However, it seems that the priorities of most universities who grant substitutions are 1) to review disability documentation to determine if a student is eligible for foreign language substitution courses, and 2) to 
decide what courses will constitute the substitution. In other words, these institutions do not assist the student in choosing the most appropriate foreign language given the student's individual strengths and weaknesses or support the student during the process of attempting foreign language study, as practiced at Northwestern University. Northwestern University therefore stands out in providing a more individualized and process-oriented model in its approach to supporting qualifying students in their attempts to study foreign language to the extent of their ability.

\subsection{Northwestern University's Position}

Consistent with the research findings described above and the limitations of psychoeducational tests with sufficient predictive validity regarding foreign language outcomes, Northwestern University has determined not to refer to a disability or LD specific to foreign language acquisition, but to refer to such students as those with "diagnosed disabilities affecting foreign language acquisition" ("High school applicants FAQs"). The University furthermore determined that the diagnostic criteria and the experience of each student with a disability must be reviewed on a case-by-case basis. This decision has been validated by the fact that the students who have received some type of accommodations in the last five years have not only been categorized as having LD (usually in the achievement areas of language, reading, or writing), but have included students who are deaf or hard-of-hearing, those diagnosed with central auditory processing disorder, attention-deficit/hyperactivity disorder (AD/HD), autism spectrum, and even students with psychological disabilities (e.g., a student with a panic disorder that was very specific to foreign language classes).

Regardless of the type of disability, each student's documentation is carefully reviewed for evidence of why foreign language would be expected to pose significant difficulties. A student with $\mathrm{AD} / \mathrm{HD}$ and no co-morbid $\mathrm{LD}$, for example, would generally be expected to struggle no more in foreign language courses than any others because attention is such a broad process. In support of this, Sparks, Javorsky, and Philips (176) found that all the college students with $\mathrm{AD} / \mathrm{HD}$ in their study were able to complete their school's foreign language requirement by taking foreign language classes; moreover, two-thirds of these students completed the foreign language requirement with no instructional accommodations. 


\section{Administrative Support for Students with Disability}

\subsection{Services For Students With Disabilities}

SSD serves over 700 undergraduate, graduate, and professional school students. ${ }^{5}$ Approximately $53 \%$ of these students have learning disabilities and/ or $\mathrm{AD} / \mathrm{HD}$, while about $21 \%$ have psychological disabilities, $16 \%$ have physical or mobility impairments, and $5 \%$ have sensory impairments. ${ }^{6}$ The majority of students who approach SSD have a history of disability documentation that extends at least as far back as high school if not elementary school. A small portion of these students expresses concerns about the foreign language requirement during their initial contact with the office. The second group of students who approach SSD are students who have no previously documented disabilities but are referred by their foreign language instructors or self-referred after struggling in their foreign language courses. These students are referred by SSD for comprehensive evaluations (usually for LD, a psychological disability, $\mathrm{AD} / \mathrm{HD}$ and/or a central auditory processing disorder) to a trusted local evaluator who can evaluate at little or no cost. ${ }^{7}$

\subsection{Variability Inherent in Language Acquisition}

Languages vary greatly from one to the next: Spanish is highly phonetically regular while English is not; Japanese represents words logographically, while English has an alphabetic system; Chinese uses tones, English does not. In addition, the variability inherent in students, even those who are found by psychoeducational testing to have a learning or other disability, poses difficulties for reliably predicting these students' foreign language learning.

In order to make the most accurate determination of which students could potentially be successful in learning a language or should qualify for some type of accommodations, a number of factors and evaluation results should be considered. For instance, Sparks and Ganschow posited the Linguistic Coding Deficit Hypothesis, meaning that weaknesses in phonological coding in one's native language are likely to be seen when one attempts foreign language as well. This hypothesis has garnered increasing support and means that many tests of students' phonological processes are relevant to the determination of who should be considered for foreign language accommodations. In addition, the language hierarchy (Myklebust 232) illustrates the intricate relationship between receptive language, expressive language, reading, and writing. Therefore, tests measuring these language 
and related skills (such as grammar, vocabulary, and encoding/spelling) and tests measuring the processes underlying language (such as phonological and orthographic processing and rapid automatic naming) may also provide important information.

A few additional processes play into language acquisition. For instance, Banerjee and Brinckerhoff posit that tests pertaining to memory (auditory, visual, short-term, etc.) also play an important role in learning a language. Moreover, assessments of fine-motor skills and pattern recognition would be essential to evaluate the aptitude of acquiring logographic languages. The job of SSD is to summarize what available testing results are applicable to a student's foreign language acquisition and present this summary to the Language Proficiency Committee. From this point on, the members of the committee and SSD make joint decisions as to foreign-language-related accommodations for which the student may qualify.

\subsection{Implications and Strategies for Inclusive Teaching and Learning}

SSD and the Language Proficiency Committee have long observed the role played by classroom environment or fit and perceived support in a student's foreign language acquisition. Their observations were corroborated by a series of three studies conducted at Longwood University by Scott, Hildebrandt, and Edwards that explored the language-learning environment from the perceptions of students with a diverse range of documented cognitive and physical disabilities (173). Various elements of the foreign language curriculum, including instruction, assessment, and the physical learning environment, were identified by these students as being important for inclusion in their learning experiences, while others were evaluated as potential barriers to learning. The findings of these studies highlight several critical areas that determine success in foreign language learning. These areas include classroom environment, instructor qualities, accommodations, multimodal teaching, and group work (Scott, Hildebrandt, and Edwards 185).

While the focus of research in these three studies is on students with disabilities, results also point to some common elements identified by students with and without disabilities. Several specific strategies were found to help language instructors begin to formulate inclusive practices for the benefit of all second-language students, those with and without disabilities (Scott, Hildebrandt, and Edwards 186-188). Instructors should

- Be flexible and adaptable with each new set of students; 
- Consider the learning needs of diverse students by designing inclusive classrooms from the outset;

- Become aware of student needs and seek out information about students that can help them;

- Be cognizant of inadvertent environmental barriers that can often easily be removed;

- Anticipate the potential barriers that traditionally sound, research-based, instructional practices may cause, for they may be experienced in different ways by different students;

- Recognize that social interaction can generate dissonance, and be thoughtful in creating groups and monitoring the output of all group partners;

- Design a classroom that anticipates the needs of students with disabilities to provide learning opportunities for those students without diagnosed disabilities as well.

This social model of disability shifts the focus from examining student deficits to considering the learning environment as a source of inadvertent barriers to diverse students. Its goal is to recognize and reduce barriers to learning in the environment, and to proactively design classroom instruction that benefits a variety of learners and addresses individual differences (Scott, Hildebrandt, and Edwards 189).

\section{Cross-Departmental Support for Students with Language Learning Difficulties}

\subsection{The Council on Language Instruction and The Language Proficiency Committee}

In order to enhance and streamline language instruction, to facilitate communication across departments, and to encourage and support the professional development of language instructors, the Weinberg College of Arts and Sciences convened the Council on Language Instruction. ${ }^{8}$ Among the responsibilities given to the council by the Dean's office is the oversight of the foreign language proficiency requirement, which means making decisions on petitions from students who are experiencing extraordinary difficulties in learning a foreign language and have a diagnosed disability affecting foreign language acquisition. The council designates these duties to one of its subcommittees, the Language Proficiency Committee. 
Currently, the Language Proficiency Committee has seventeen members representing nine different departments or programs. Most members of the committee serve as Language Proficiency Advisors (LPAs). These advisors accompany students throughout their foreign language course work by serving as liaisons to academic advisors, to the $\mathrm{SSD}$, and to language instructors.

\section{Students Petition for Language Learning Support}

Although there are some students who are dismayed that there is no language waiver at Northwestern University, as mentioned earlier, there are also many students with disabilities who are reluctant to request or accept accommodations (due to stigma or other concerns). They want to be treated as much like other students as possible, which means attempting foreign language classes and completing as much of the language requirement without substitution classes as possible. Cognizant of this latter group of students and in order to comply with all legal and pedagogical requirements, the Language Proficiency Committee developed a petitioning procedure for students who have a diagnosed disability affecting foreign language acquisition. ${ }^{9}$

\subsection{Contact with Services for Students with Disabilities}

The first step in the process is to contact SSD. At this time, the student provides documentation of a disability affecting foreign language acquisition. The director will evaluate the documentation and decide whether an accommodation may be appropriate. If a student has no such documentation, or if the documentation is incomplete, the director suggests testing by a third party. The director will then write a summary letter describing the impact of the student's disability in learning a foreign language. This letter will accompany the student's petition for the appointment of a Language Proficiency Advisor.

\subsection{Working with a Language Proficiency Advisor}

Each student completes a "Petition for Appointment of a Language Proficiency Advisor" and submits it to the Language Proficiency Committee. Members of the committee will review the petition and summary letter from SSD. If the committee concludes that some form of advising including possible accommodation is warranted, the chair of the committee will then assign an LPA to the student. 
The LPA will arrange for the student to take a placement exam if she/he has previously studied a foreign language or will finalize the selection of an appropriate foreign language class if she/he is to begin a new language. If the student is currently enrolled in a foreign language class, the LPA will consult the student's current and past language instructors to verify the efforts being put forth by the student inside the classroom and on homework. On the basis of the collected information and recommendation by the LPA, the members of the Language Proficiency Committee will decide whether the student should:

- continue with the current foreign language sequence (possibly under a pass/ no pass grading arrangement) until the foreign language requirement is fulfilled;

- finish the current course but complete the remainder of the foreign language requirement through substitute course work; or

- drop the current course and complete the requirement through substitute courses.

If a decision is made by the Language Proficiency Committee to allow the student to complete the remainder of the requirement through substitute course work, the LPA, together with the student, will then design a coherent set of substitute courses (i.e., the substitution list) built around the language courses completed. This list is presented to the committee for approval. The LPA will continue to work with the student to make sure progress is made and will also present regular updates to the committee. Once the student has successfully passed all the required foreign language courses or courses on the approved substitution list, the student has officially passed the foreign language requirement. The steps of this process are outlined in Table 1.

\subsection{Designing a Substitution List: Combining Language Classes and Related Classes}

The Language Proficiency Committee has guidelines for the inclusion of classes on a student's substitution list but no pre-set model. Each substitution list is worked out in consultation with the student and the appropriate language department to design a coherent program that will benefit the student and maximize exposure to one language and its culture. Courses on the substitution list may include courses on literature in translation, translation courses, culture 
A CROSS-DEPARTMENTAL APPROACH

Table 1: Application Procedure and Support for Learning a Foreign Language

Services for Students with Disabilities (SSD)

Student was already
diagnosed with a
disability.

\section{Student experienced difficulties in FL in Junior High and High School.}

SSD evaluates diagnosis. If warranted SSD writes recommendation to $C L I$ or requests more documentation. Student fills our request for LPA.

SSD reviews case and suggests testing by third-party if pre-screen warrants it.
Student may decide to avoid FL classes by transferring out.

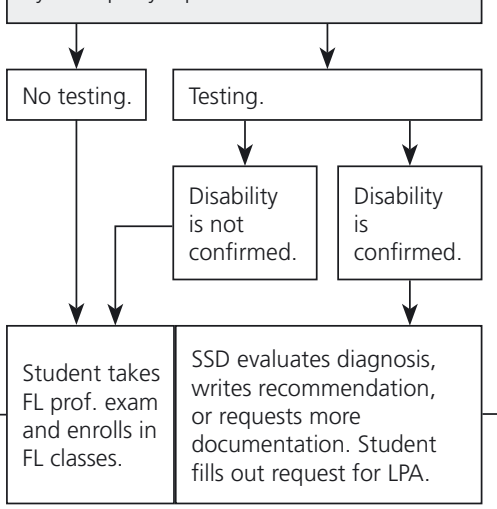

Student is currently enrolled in a FL class and is experiencing difficulties.
SSD reviews case and suggests testing by third-party if pre-screen warrants it.

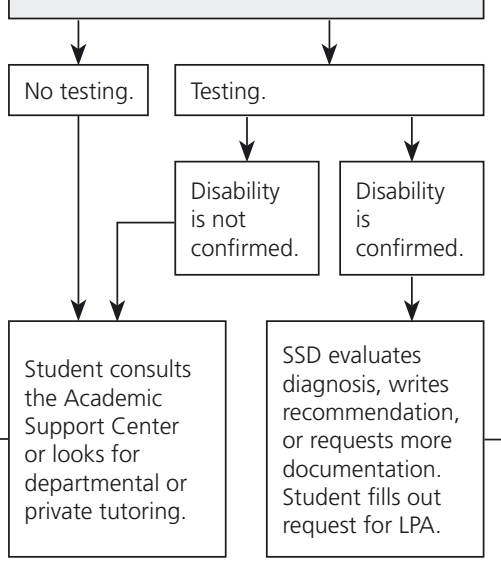

Cimittee on Language Proficiency

Chair of CLP assigns LPA if in agreement wth SSD

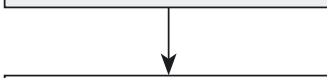

LPA develops plan with student and language instructor(s) to attempt as many FL classes as she/he can pass successfully in chosen language.

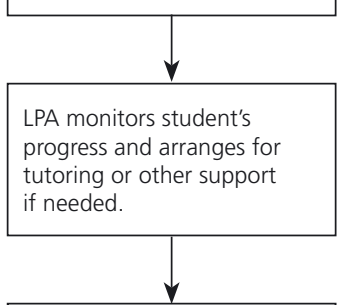

If necessary, LPA works out substitution plan with student and presents it to CLP for approval.

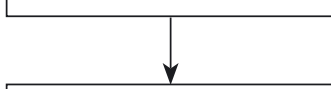

Chair of CLP informs student $\&$ College Counselor of approved substitution plan.

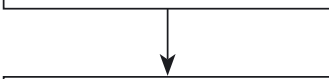

LPA works with student until FLR is fulfilled. Submits periodic reports to CLP.

Chair of CLP informs student
$\&$ College Counselor, and
Registrar's office that student
has fulfilled the FLR.


courses, or courses in history or politics. Below are three examples of courses students took to fulfill the foreign language requirement. It is noteworthy that both of their language choices were of cultural significance to them.

Student \# 1. This student had a history of diagnosed LD in grade school but had not been reevaluated or received services since then. After he began struggling in Chinese, he was reevaluated. His reevaluation affirmed the existence of ongoing LD, and the nature of his disability (which included fine-motor and visual-perceptual weaknesses) made it clear that foreign language, and Chinese in particular, was a tough choice for him. However, he was already a junior and it was too late for him to attempt a different language. This student had completed the first year of Chinese. The Language Proficiency Committee then approved three complementary substitute courses to fulfill the second year of the foreign language requirement (two history courses on China and one political science course on Chinese politics).

Student \# 2. This student was failing the first quarter of beginning Hebrew, despite the fact that she had attended Hebrew school as a child. She indicated that her other courses were suffering because she spent all of her time trying to learn Hebrew. She had already attempted other languages (French and Spanish) in middle and high school and had received low grades. She was a transfer student with updated disability documentation. Because of her Jewish heritage, she wanted to choose courses with that theme. The Language Proficiency Committee approved a six-course substitution in Jewish Culture and History and in Jewish studies.

Student \# 3. This student had a long history of dyslexia (learning disability that impacts reading/decoding and spelling) and received over 10 years of tutoring to address these weaknesses. Although he had done well in 5 years of French in elementary and secondary school through hard work and assistance from his mother (a French teacher), he placed into only the intermediate level (second year) of French at Northwestern University. Due to the difficulty he was experiencing in his Intermediate French course, however, he dropped back to taking Elementary French, which he completed independently. Upon restarting the Intermediate French series, he realized that he might be reaching his limit. Since French is not highly phonetically regular, it was not the best choice for the student, but he needed to continue in French since he was beginning his senior year (meaning he did not have time to complete two years 
of an alternate language). He therefore applied for and was approved for an LPA to assist in his second and final year of French. His LPA advocated for him to take his remaining courses on a Pass/Fail versus graded basis, which the Language Proficiency Committee approved. The student is about to complete his 2-year French requirement with no substitution courses.

\section{Evaluation of the Program}

Between the years 2003-2013, the period the program has been in existence, a total of 56 students were referred to the Language Proficiency Committee and were assigned LPAs to help them finish their foreign language requirement. Of those 56,12 students chose an interschool transfer or a transfer to another university with a less stringent or no language requirement. Of the remaining 44 students, 35 have already finished the foreign language requirement. Of those, 14 students completed it entirely with language courses despite their having had difficulties prior to receiving support from an LPA. The remaining 21 students completed the language requirement with a combination of language courses and substitute courses in literature/culture, history, and political science. On average, these 21 students completed 2.7 language courses with the help of an LPA before taking substitute courses.

We consider this a huge success, as did the students, most of whom wanted to complete the language requirement as much like other students as possible. The success of the program can be attributed to several reasons:

- The diagnostic summary written by SSD about test results, background of student, and achievement potentials (including a basic assessment of why certain languages might prove more difficult than others) provides a clear picture of the likelihood that a student will succeed in foreign language classes and what accommodations she/he might need such as extra time on tests.

- The regular meetings and communications between the staff of SSD and the members of the Language Proficiency Committee assures that questions about the student's background, current classroom performance, and progress with the LPA can be discussed in an ongoing, timely fashion.

- The discussion of each case among the members of the committee, composed of language coordinators and language instructors representing several language departments and many different languages, ensures that 
a student's needs are considered on a variety of levels and best practices are being put forth.

- The assignment of a special advisor (the LPA) to each case, whose task it is to find the best solution for the student, assures that best decisions are being made based on current information and that the student has a contact person with whom to discuss problems as they arise. Classes are selected based on a student's strengths; instructors are selected based on their willingness to work with a student inside and outside of class; and accommodations such as more time on exams, tutoring where appropriate, and pass/fail grading are put in place.

\section{Future Directions}

The process we have outlined in this paper has worked well for our university. We are confident that we are offering the best help to students who are diagnosed with a disability affecting language learning. We also feel that the language courses coupled with appropriate replacement courses to complement the language courses are an appropriate substitution for the foreign language requirement. As the numbers above prove, students do feel confident with the support they receive to continue with learning a language. We would, of course, like to be able to offer the same level of assistance to students who simply struggle with foreign languages for reasons other than a disability.

As with every process, however, there are areas for enhancement. We are currently discussing how to improve the information flow between LPAs, language instructors, departmental advisors, academic and athletic (if applicable) advisors, and the students themselves. We are also seeking ways to identify students early in their college studies so that they have ample time to finish the required course work. This includes students who are reluctant to admit that they have a problem due to the perceived stigma of a disability. ${ }^{10}$

In our work with students we have seen a continuum from very good to very poor language learners. We have noticed that there are many students with a disability who can learn a foreign language and there are students without a disability who cannot. The former students are well served by our advising process, the latter are not. Consistent with Sparks's ("Evidence-based accommodation decision making" 182) recommendation, we would very much like to open up the process to individuals who have a longstanding history of foreign language difficulties/failures, but who have not received a disability diagnosis. We believe a better mentoring process including the guidance of an 
LPA would ensure that they too would successfully pass the foreign language requirement. This, however, would mean more responsibilities and more hours for the volunteer LPAs, especially as the number of students registering with SSD is increasing.

The University has a number of advising centers with whom we are exploring the possibility of working more closely. The SEARLE Center for Advancing Learning and Teaching, for example, is currently hosting an Academic Mentoring Program in collaboration with the University Academic Advising Center for students having difficulties in large undergraduate introductory courses. Our idea is to develop a similar program tailored to foreign language learners in which undergraduates who are excellent foreign language learners would provide academic support to their fellow students having trouble with learning a foreign language. ${ }^{11}$ This could also include a detailed questionnaire to identify students who feel particularly anxious about speaking up in language classes and offer them special help to overcome these symptoms.

We are also discussing the feasibility of taking our process one step further to make it more like Colorado's Modified Foreign Language Program (Regents of the University of Colorado), which has smaller, sheltered sections of foreign language classes that are taught by foreign language instructors who are accustomed to doing more individualized/specialized instruction. The Modified Foreign Language Program, however, still serves only students who have been diagnosed with a disability. The true spirit of a foreign language accommodation would be that universities would offer sheltered sections with individualized instruction to all students struggling to learn a foreign language.

\section{Notes}

1. The report states: "An individual's level of proficiency will vary between the four dimensions (listening, speaking, reading and writing) and between the different languages, and according to that individual's social and cultural background, environment, needs and/or interests" (Recommendation of the European Parliament and of the Council).

2. The level of achievement required for a foreign language requirement varies according to schools, departments, and language(s). As an example, for students passing the foreign language requirement in German at Northwestern University, the level of proficiency achieved ranges from Intermediate Mid to Intermediate High on the ACTFL oral proficiency scale (B1 on the Common European Framework of Reference (CEFR)). The overall goal for the German program is for the best students to reach the Advanced High Level on the 
ACTFL oral proficiency scale ( $\mathrm{Cl}_{1}$ on the Common European Framework of Reference (CEFR)) by the time they finish a major in German.

3. For a recent discussion and in-depth review of the issues associated with first and second language acquisition see, for example, Cook's essay "The relationship between first and second language acquisition revisited".

4. Ellis and Wells, for example, showed that variations in speed of children's language acquisition can be explained by the quality of input children receive.

5. Northwestern has about 8,ooo full-time undergraduates and 8,ooo full-time graduate students ("Northwestern Facts").

6. The mission of SSD is to ensure that all Northwestern University students with disabilities have the opportunity to fully participate in the academic programming and all other facets of University life. The office carries out its mission through its commitment to accessibility and diversity and its provision of reasonable accommodations and direct service to students with disabilities ("Getting to know the office").

7. SSD has made arrangements with Northwestern University's financial aid office and local evaluators in an attempt to defray as many expenses as possible from students who pursue further evaluation. Moreover, Northwestern University has on-site health and psychological services offices that can provide diagnostic services at no cost (in many circumstances).

8. Language coordinators from all language departments or programs serve as members of the Council. During the academic year, the council organizes workshops, seminars, talks, and symposia dealing with current research on $\mathrm{L}_{2}$ and applied and practical matters in language teaching to assure uniform high teaching standards across departments.

9. This procedure was developed in conjunction with the Associate Dean for Undergraduate Study, the Assistant Dean for Academic Standing of the Weinberg College of Arts and Sciences, the Council on Language Instruction, the Director and the Assistant Director of SSD, and the Language Proficiency Committee. Deans from the other undergraduate schools whose degree requirements include a foreign language requirement were consulted. This petition was examined and approved by the University attorneys' office.

10. Quite often, students come to us only towards the end of their studies, leaving little other choice than taking intensive language classes during the summer, or signing up for more than one substitution class per quarter.

11. For a description of a good language learner, see Rubin and more recently Griffiths.

$\begin{array}{ll}\text { Abbreviations } \\ \text { ACTFL } & \text { American Council on the Teaching of Foreign Languages } \\ \text { AD/HD } & \text { Attention Deficit/Hyperactivity Disorder } \\ \text { CEFR } & \text { Common European Framework of Reference } \\ \text { CLI } & \text { Council on Language Instruction } \\ \text { CLP } & \text { Committee on Language Proficiency } \\ \text { FL } & \text { Foreign Language } \\ \text { FAQ } & \text { Foreign Language Acquisition } \\ \text { FLLD } & \text { Foreign Language Learning Disability }\end{array}$




$\begin{array}{ll}\text { GPA } & \text { Grade Point Average } \\ \text { LD } & \text { Learning Disability } \\ \text { LPA } & \text { Language Proficiency Advisor } \\ \text { L1 } & \text { First Language } \\ \text { L2 } & \text { Second Language } \\ \text { MLAT } & \text { Modern Language Aptitude Test } \\ \text { SSD } & \text { Office of Services for Students with Disabilities }\end{array}$

\section{Works Cited}

"Advisee handbook: A student guide to the Brown first-year advising process made by the students, for the students." Brown University. 2012. Web. 27 June 2013.

Banerjee, Manjushri and Loring Brinckerhoff. Beyond disability documentation: Solutions, strategies and sage advice regarding accommodations. Learning Disabilities Association of America Conference, Chicago. 22-25 February 2012. Web. 25 June 2013.

Calvin, Lisa M. and Anne N. Rider. "Not your parents' language class: Curriculum revision to support university language requirements." Foreign Language Annals. 2004. 37. 11-22. Print.

Carroll, John Bissell and Stanley M. Sapon. Modern Language Aptitude Test, Form A. Bethesda, MD: Second Language Testing, Inc. 1999. Print.

Cook, Vivian. "The relationship between first and second language acquisition revisited." In Ernesto Macaro (Ed.) The Continuum Companion to Second Language Acquisition. Continuum Companions. 2010. 137-57. Print.

"Colorado modified foreign language program." Speech, language, and hearing sciences. Regents of the University of Colorado. 2013. Web. 25 June 2013.

"Course substitutions." Penn State Altoona. 2012. Web. 25 June 2013.

Donato, Richard and Frank B. Brooks. "Literacy discussions and advanced speaking functions: Researching the (dis)connection." Foreign Language Annals. 2004. 37(2), 183-199. Print.

Ellis, Rod. Learning a Second Language through Interaction. Amsterdam: John Benjamins. 1999. Print.

Ellis, Rod and Gordon Wells. "Enabling factors in adult-child discourse." First Language. 1980. 1. 46-82. Print.

"Foreign language course substitution policy." Academic Affairs at Penn State Altoona. 1 December 2008. Web. 15 June 2013.

"Foreign language requirement accommodation." Weinberg College of Arts \& Sciences at Northwestern University. 28 Sept. 2012. Web. 27 June 2013. 
"Foreign language substitution package." College of Letters and Sciences, University of Wisconsin-Madison. n.d. Web. 22 June 2013.

Forsbach-Rothman, Terri, Fernando F. Padro, and Jennifer Rice-Mason. "Course substitution practices, policies, and implications for students with disabilities." NACADA fournal. 2005 . 25 17-25. Print.

Fowler, Claire, Hendrik Hartog, John Kolligian, Andrea LaPaugh, Erin McDermott, Jean Schwarzbauer, and Dmitri Tymoczko. Report of the provost's ad hoc advisory committee on disability services for undergraduates. 21 Feb 2011. Web. 25 June 2013.

Gajar, Anna H. "Foreign language learning disabilities: The identification of predictive and diagnostic variables." Fournal of Learning Disabilities. 1987. 20. 327-30. Print.

Gass, Susan M. Input, Interaction, and the Second Language Learner. Mahwah, NJ: Lawrence Erlbaum Associates. 1997. Print.

Gass, Susan. M. and Larry Selinker. Second Language Acquisition: An Introductory Course (2nd edition). Mahwah, NJ: Lawrence Erlbaum Associates. 2001. Print.

Gass, Susan M and Evangeline M. Varonis. "Input, interaction, and second language production." Studies in Second Language Acquisition. 1994. 16. 283-302. Print.

"Getting to know the office." Services for Students with Disabilities at Northwestern University. 2013. Web. 27 June 2013.

Griffiths, Carol (Ed.). Lessons from Good Language Learners. Cambridge: Cambridge University Press. 2008. Print.

"High school applicants FAQs." Northwestern University, Office of Undergraduate Admission. n.d. Web. 27 June 2013.

Horwitz, Elaine K. "Language anxiety and achievement." Annual Review of Applied Linguistics. 2001. 21. 112-27. Web. 30 December 2013.

Horwitz, Elaine K., Michael B. Horwitz and Joann Cope. "Foreign language classroom anxiety." The Modern Language fournal. 1986. 70(2). 125-32. Web. 30 December 2013.

$\mathrm{Hu}$, Chieh-Fang. "Phonological memory, phonological awareness, and foreign language word learning." Language Learning. 2003. 53 - 429-62. Print.

Jarrow, Jane and Ruth Fink. Making the grade when responding to course substitution requests. Proceedings from the Thompson Interactive audio conference. 8 February 2005. Web. 25 June 2013.

Krashen, Stephen. Second Language Acquisition and Second Language Learning. Oxford: Pergamon. 1981. Print. 
---. The Input Hypothesis: Issues and Implications, New York: Longman. 1985. Print.

"Language requirement substitution." College of Arts and Sciences at University of Pennsylvania. n.d. Web. 23 June 2013.

"Language substitution." Newnan College of Literature, Science \& the Arts Academic Advising Center at University of Michigan-Ann Arbor. 2012. Web. 25 June 2013 .

Larsen-Freeman, Diane and Michael H. Long. An Introduction to SecondLanguage Acquisition Research. New York: Longman. 1991. Print.

Liu, Meihua and Wenhong Huang. "An exploration of foreign language anxiety and English motivation." In Education Research International. 2011. 1-8. Web. 30 December 2013.

Mackey, Alison and Jenefer Philp. "Conversational interaction and second language development: Recasts, responses, and red herrings." The Modern Language fournal. 1998. 82. 338-56. Print.

Mangrum, Charles T. and Stephen S. Strichart. Colleges with Programs for Students with Learning Disabilities. Princeton, NJ: Peterson's Guides. 1992. Print.

Mantero, Miguel. "Bridging the gap: Discourse in text-based foreign language classrooms." Foreign Language Annals. 2002. 35 4 437-56. Print.

Marinis, Theodore. "Psycholinguistic techniques in second language acquisition research." Second Language Research. 2003. 19(2). 144-61. Print.

Myklebust, Helmer R. The Psychology of Deafness ( $2^{\text {nd }}$ ed.). New York: Grune \& Stratton. 1965. Print.

"Northwestern Facts." Web. 25 May 2014.

Olivares-Cuhat, Gabriela. "Relative importance of learning variables on L2 performance." Linguistik online. 2010. 43(3). 99-116. Web. 30 December 2013 .

Otto, Beverly. Language Development in Early Childhood ( $2^{\text {nd }}$ ed.). Upper Saddle River, New Jersey. 2006. Print.

Pager, Tyler. "Northwestern's Acceptance rate drops to record-low 12.9 percent." Daily Northwestern (2014, March 22). Web. 25 May 2014.

Pica, Teresa. "Research on negotiation: what does it reveal about secondlanguage learning conditions, processes, and outcomes?" Language Learning. 1994. 44. 493-527. Print.

Recommendation of the European Parliament and of the Council of 18 December 2006 on key competences for lifelong learning. Official Journal of the European Union L394/10. Web. 15 April 2014. 
"Reasonable accommodations and services." Services for Students with Disabilities at Northwestern University. 2013. Web. 27 June 2013.

Rubin, Joan. 1975. "What the 'good language learner' can teach us." In TESOL Quarterly, 9(1) (March 1975). 41-51. Web. 30 December 2013.

Russell, Louise H. "The transition to college: Practice doesn't always make perfect." Perspectives, the newesletter of The International Dyslexia Association 28 (2002). Web. 15 June 2013.

Section 504 of the Vocational Rehabilitation Act, 77 U.S.C., $\$ 794$ (1973).

"Skills requirements." Yale College. 2013. Web. 27 June 2013.

Scott, Sally S., Susan A. Hildebrandt, Wade A. Edwards. "Second language learning as perceived by students with disabilities." In Cristina Sanz, Beatriz Lado (Eds.) Individual differences, L2 development, and language program administration: From theory to application. 2013. 171-91. Print.

Sparks, Richard L. "Is there a 'disability' for learning a foreign language?" Journal of Learning Disabilities. 2006. 39. 544-57. Print.

---. "Evidence-based accommodation decision making at the postsecondary level: Review of the evidence for foreign language learning." Learning Disabilities Research \& Practice 23(2008). 180-83. Print.

Sparks, Richard L. and Leonore Ganschow. "Searching for the cognitive locus of foreign language learning difficulties: Linking first and second language learning." The Modern Language fournal. 1993 · 77. 289-302. Print.

Sparks, Richard L., James Javorsky and Lois Philips. "College students classified with ADHD and the foreign language requirement." Fournal of Learning Disabilities. 2004. 37. 169-78. Print.

Sparks, Richard L., Lois Philips, Leonore Ganschow, and James Javorsky. "Students classified as LD and the college foreign language requirement: A quantitiative analysis." Journal of Learning Disabilities. 1999 - 32. 566-8o. Print.

Sparks, Richard L., Lois Philips, and James Javorsky. "Students classified as LD who received course substitutions for the college foreign language requirement." Journal of Learning Disabilities. 2002. 35 482-99, 538. Print.

---. "Students classified as LD who petitioned for or fulfilled the foreign language requirement-Are they different? A replication study." Fournal of Learning Disabilities. 2003. 36. 348-62. Print.

Trustees of Dartmouth College. "Prospective students." Student accessibility services. 2013. Web. 27 June 2013. 
White Paper on Education and Training - Teaching and Learning Towards the Learning Society. COM (95) 590 final, 29 November 1995. [EU Commission - COM Document]. Web. 15 April 2014.

Ziegler, Johannes. C. and Usha Goswami. "Reading acquisition, developmental dyslexia, and skilled reading across languages: A psycholinguistic grain size theory." Psychological Bulletin, American Psychological Association. 2005. 131(1). 3-26. Print. 